\title{
Anterior dislocation of the restrained shoulder: a seat-belt injury
}

A. A. SALAM*, K. S. EYRES, A. D. MAGIDES, \& J. CLEARY*

* Department of Orthopaedics, Huddersfield Royal Infirmary, Huddersfield; Department of Orthopaedics, King Edward VII Hospital, Sheffield and; Anaesthetic Registrar, Royal Hallamshire Hospital, Sheffield

\section{SUMMARY}

The reduction in morbidity and mortality since the enforcement of seat-belt usage is well documented. Complications from the belt are also reported and the authors $ᄋ$ present anterior dislocation of the restrained shoulder, an injury not previously $\vec{\bullet}$ described.

The mechanism of injury is explained and a change to the present standard restraints is suggested.

\section{INTRODUCTION}

With conventional three-point seat-belts, a differential restraint is placed across the upper body. As a result, the authors describe anterior dislocation of the restrained shoulder following a road-traffic accident. Such an injury has not been previously reported and gives further support to a change in the conventional seat-belt design.

\section{CASE REPORT}

A 33 year-old driver was involved in a head-on collision whilst wearing a seat- $\tilde{\sim}$ belt. Following the impact, the right shoulder was dislocated anteriorly (subcoracoid). Although the patient could not remember the accident, the unharmed $\bar{Q}$

Correspondence: Mr. A. A. Salam, Orthopaedic Department, Huddersfield Royal Infirmary, Acre Street, Linley, Huddersfield HD3 3EA, U.K. 
passenger described him driving with the right shoulder abducted and the elbow resting on the door edge. There was no associated fracture, nor previous history of dislocation or instability. The brachial plexus was intact and there was no clavicular fracture. General anaesthesia was required for satisfactory reduction and no further problems have been encountered.

\section{DISCUSSION}

The beneficial effects of seat-belt usage are well reported since the enforcement in England on 1 February 1983. (Allen et al., 1985).

Cambell analysed the injuries sustained in over 1.5 million patients in road accidents in North Carolina, and stated that seat-belts reduced the incidence of serious injury by $51-52 \%$ and of fatal injuries by $63-67 \%$. (Campbell, 1987) Death may be as much as four times more likely to occur without seat-belt usage (Christian, 1984).

Whilst observing the benefits of driver and passenger restraints, The Oxford Road Accident Group noticed an increase in the number of closed head and facial injuries following seat-belt usage from impact with the steering wheel. (Tunbridge et al., 1988). Blunt injuries to the spine, thorax, intraperitoneal structures and aorta have also been well documented. (Warrian et al., 1988; Arajarvi, 1989) Abrasions and contusions from the belt have been termed the 'seat-belt sign'. Reath et al., (1989) studied the patterns of maxillofacial injuries in restrained crash victims and concluded that although the number of fracture to the upper and mid face were reduced, the number of mandibular injuries was unchanged (Reath et al., 1989). With conventional three point seat-belts there is a differential restraint across the upper thorax. This results in rotation to the right and impact of the left side of the head and face on the steering wheel. The distribution of right or left rib fracture then depends on the side of maximum loading caused by the seat-belt (Newman \& Jones, 1984 Gallup \& Newman, 1987).

The seat-belt can also cause local injuries as it passes across the clavicle to its fixation point. Ernst described a case of carotid artery injury as a direct result of compression across neck from the seat-belt (Ernst et al., 1988).

Marrero reported traumatic injury to the right brachial plexus resulting in lateral pectoral nerve palsy similarly due to a compressive force from the belt (Marrero \& Goldfine, 1989). Arajarvi describes clavicle fractures in $14.8 \%$ of fatal injuries in restrained victims (Arajarvi \& Santavirta, 1989). The mechanism of injury in this case is as follows. With the shoulder abducted and elbow flexed resting on the door ledge, the seat-belt passed over the antero-superior part of the shoulder. The impact of the body against the belt subsequently forced the humeral head downwards, whilst the thorax was restrained. As the unrestrained right arm moved forwards, the shoulder dislocated.

The evidence from this case suggests, as other authors have, that a symmetrical restraint system is employed, correctly fitting and with larger support pads across the shoulder. 


\section{REFERENCES}

Allen M. J., Barnes M. R. \& Bodiwala G. G. (1985) The effect of seat-belt legislation on injuries sustained by car occupants. Injury 16; 471-6.

Arajarvi E. \& Santavirta S. (1989) Chest injuries sustained insevere traffic accidents by seat-belf wearers. Journal of Trauma 29, 37-41.

Campbell B. J. (1987) Safety belt injury reduction related to crash severity and front seated position Journal of Trauma 27, 733-9.

Christian M. S. (1984) Morbidity and mortality of car occupants: A comparative study over 24 months British Medical Journal 289, 1525-6.

Ernst A., Robertson H. J., Bercier M. L. et al. (1988) Occult carotid artery injury related to automobile seat-belt. Annals of Emergency Medicine 17, 1091-4.

Gallup B. M. \& Newman J. A. (1987) The assessment of facial injury to fully restrained drivers through full scale car crash testing. Journal of Trauma 27, 711-7.

Hudson I. \& Kavanagh T. G. (1983) Duodenal transection and vertebral injury occurring in combination in a patient wearing a seat belt. Injury 5, 6-9.

Marrero J. L. \& Goldfine L. J. (1989) Isolated lateral pectoral nerve injury: Trauma from a seat-belt 3 Archives of Physical Medicine and Rehabilitation 70 (3), 239-40.

Newman R. J. \& Jones I. S. (1984) A prospective study of 413 consecutive car occuparits with chest injuries. Journal of Trauma 24, 129-35.

Reath D. B., Kirby J., Lynch M. et al. (1989) Patterns of maxillofacial injuries in restrained and unre윽 strained motor vehicle crach victims. Journal of Trauma 29 806-10.

Tunbridge R. J., Everest J. T., Wild B. R. \& Johnstone R. A. (1988) An in-depth study of road acciden $\bar{Z}$ casualties and their patterns. TRRL. Res. Rep., 136. Crowthorne, Berkshire Transport And Roaकू Research Laboratory.

Warrian R. K., Shoenut J. P., Iannicello C. M. et al. (1988) Seat-belt injury to the abdominal aortace Journal of Trauma 28, 1505-7. 